\title{
Ileal Perforation due to Pyloric Stent Migration in a Patient with Inoperable Gastric Cancer
}

\author{
Mehmet Tolga Kafadar' (D), Gurkan Degirmencioglu² (D), Aydin Inan ${ }^{3}$ \\ 'Department of General Surgery, Health Sciences University Mehmet Akif Inan Training and Research Hospital, Sanliurfa, Turkey \\ 2Department of General Surgery, Yildirim Beyazit University School of Medicine, Ankara, Turkey \\ ${ }^{3}$ Clinic of General Surgery, Ankara Umut Hospital, Ankara, Turkey
}

Cite this article as: Kafadar MT, Degirmencioglu G, Inan A. Ileal perforation due to pyloric stent migration in a patient with inoperable gastric cancer. Eurasian J Emerg Med. 2018; 17 (3): 143-4.

Gastric cancer is among the most common cancer types and predominantly involves the gastric antrum. When advanced, gastric antral cancer usually obstructs the gastric pylorus, a condition also known as gastric outlet obstruction. Whereas surgical relief of the obstruction is possible, most patients with advanced surgery is not possible. Moreover, gastric decompression, parenteral nutrition, and percutaneous enteral nutrition are not beneficial to the overall quality of life of these patients (1). In recent years, a novel approach, expandable metallic stent deployment, has been developed for esophageal and gastric cardiac strictures, but this approach is yet to be tested on a wide scale for use in gastric outlet obstruction of malignant origin. Although stent placement is a safe and effective method, complications increase the morbidity and mortality rates (2). Herein, we present a rare cause of acute abdomen in a patient with obstructive inoperable gastric cancer who had small bowel perforation as a consequence of a migrated pyloric stent.

A 45-year-old female was admitted to the emergency department of our hospital with complaints of abdominal pain, abdominal distension, and vomiting for 2 days. Her past medical history included inoperable gastric antral cancer (adenocarcinoma) for 6 months. She underwent pyloric stent placement performed by a gastroenterologist after a pyloric stricture dilatation procedure 3 months ago. In the laboratory examinations, WBC level was $15600 / \mathrm{mm}^{3}$, CRP level was $40 \mathrm{mg} / \mathrm{dL}$, and other parameters were normal. On abdominal examination, there was generalized tenderness with rebound. Computed tomography showed that the stent had migrated. With these findings, laparotomy was performed, and laparotomy revealed a perforation at the ileal segment approximately $40 \mathrm{~cm}$ away from the cecum due to the migrated pyloric stent (Figure 1a, b). Enterotomy was performed, and the stent was removed from the intestine (Figure 1c-f). A 10-cm-long ileal segment, including the perforation area, was resected, and end-to-end anastomosis was performed. The patient was transferred to the intensive care unit for postoperative care where clinical issues were addressed by a multidisciplinary team. She was discharged with full recovery after 7 days of hospitalization because no problems or complications were observed. Follow-ups over 2 months after the surgery were uneventful. Informed consent was obtained from the patient who participated in this case.

Pyloric stent placement is a technique usually performed to relieve benign strictures and fistulas, but it is also performed for palliation in patients with gastric cancer. For the latter indication, the stenting procedure is a relatively low-complication procedure and provides satisfactory symptomatic relief from debilitating symptomatology of gastric outlet syndrome originating from non-curable malignant conditions. One common complication after deployment of a stent is its migration, which is mostly asymptomatic but may still lead to potentially catastrophic consequences, such as fistula formation, hemorrhage, obstruction, and perforation. It is possible that migrating stents are discharged via the rectum; alternatively, they may remain in the body for long periods without posing any gross threat $(3,4)$.

In conclusion, endoscopic stent placement should be considered a first-line treatment to overcome gastric outlet obstruction in patients with gastric cancer who have a limited life expectancy and who are not candidates for surgery. Although rare, intestinal perforation can arise as a potentially fatal complication of stent migration.

ORCID IDs of all authors: M.T.K. 0000-0002-9178-7843; G.D. 0000-0003-1016-7085. 

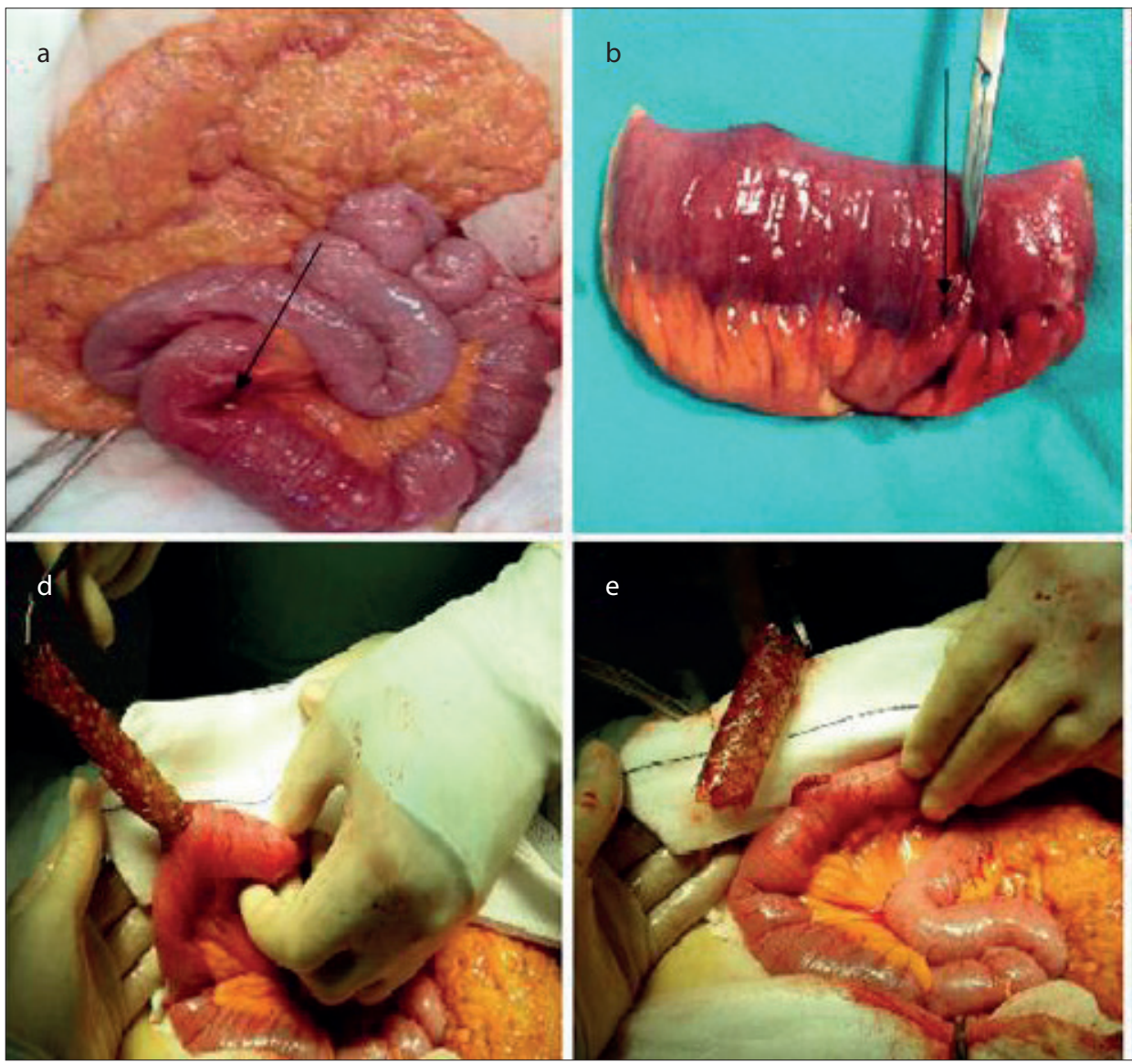

Figure 1. a-f. Perforated part of the ileum $(a, b)$, and migrated pyloric stent (c-f)

Informed Consent: Informed consent was obtained from the patient who participated in this case.

Author Contributions: Concept - M.T.K.; Design - M.T.K., A.I.; Supervision M.T.K., A.I.; Resources - M.T.K., G.D.; Materials - M.T.K., G.D.; Data Collection and/or Processing - M.T.K., G.D.; Analysis and/or Interpretation - M.T.K.; Literature Search - M.T.K.; Writing Manuscript - M.T.K.; Critical Review - M.T.K., A.I.

Peer-review: Externally peer-reviewed.

Conflict of Interest: The authors have no conflict of interest to declare.

Financial Disclosure: The authors declared that this study has received no financial support.

\section{References}

1. Wang ZY, Sun LW, Wu JL, Li L, Ma JM, Hu JD. Management of Malignant Gastric Outlet Obstruction with Expandable Metallic Stent Placement. Gastroenterology Res. 2008; 1: 40-4. [CrossRef]

2. Javaid MR, Yusuf AM. An instant rare complication: a fractured metallic pyloric stent. BMJ Case Rep. 2013; 2013: bcr2012007695.

3. Stawowy M, Kruse A, Mortensen FV, Funch-Jensen P. Endoscopic stenting for malignant gastric outlet obstruction. Surg Laparosc Endosc Percutan Tech 2007; 17: 5-9. [CrossRef]

4. Kawabata R, Kimura Y, Kawase T, Kitamura S, Yabuta T, Tsukamoto Y, et al. Gastroduodenal stent placement in gastric cancer patients with pyloric stenosis. Gan To Kagaku Ryoho. 2013; 40: 1684-6. 